\title{
Inclusion complexation of tetrabutylammonium iodide by cyclodextrins
}

\author{
BISWAJIT DATTA, ADITI ROY and MAHENDRA NATH ROY* \\ Department of Chemistry, University of North Bengal, Darjeeling, West Bengal 734 013, India \\ E-mail: mahendraroy2002@yahoo.co.in
}

MS received 7 February 2017; revised 15 March 2017; accepted 24 March 2017

\begin{abstract}
Host-guest inclusion complex of an ionic solid (tetrabutyl ammonium iodide) with $\alpha$ - and $\beta$ cyclodextrin has been explored by various physicochemical and spectroscopic methods. Surface tension and conductivity studies indicated 1:1 stoichiometry of the inclusion complexes and ${ }^{1} \mathrm{H}$ NMR and FT-IR studies substantiated the inclusion phenomenon. Density, viscosity and refractive index studies characterized the interactions of cyclodextrin with tetrabutyl ammonium iodide, which also indicated greater extent of encapsulation in $\beta$-cyclodextrin than in $\alpha$-cyclodextrin. Hydrophobic effect, structural effect, electrostatic force and $\mathrm{H}$-bonding interactions were mainly exploited to explicate the formation of inclusion complex.
\end{abstract}

Keywords. $\alpha$ - and $\beta$-Cyclodextrins; ionic solid; inclusion complex.

\section{Introduction}

In chemistry and biochemistry, cyclodextrins (CDs) are studied with immense interest due to their unique property of controlled release of molecules through the innovation of inclusion complex (IC) with guest molecules in the hydrophobic cavity. ${ }^{1}$ In diverse industries including pharmaceutical, food, textile, pesticides, cosmetics, etc., cyclodextrins have enormous applications. ${ }^{2}$ CDs are cyclic oligomer of $\alpha$-D-glucose having numerous of glucopyranose units $(6$ in $\alpha-C D, 7$ in $\beta-C D$ and 8 in $\gamma$-CD) bound by $\alpha-(1-4)$ linkages. ${ }^{3}$ CDs are truncated cone-shaped structures with a quite rigid and distinct hydrophobic cavity of varying diameter and two separate rims; all the secondary hydroxyl groups forming a wider rim and all the primary hydroxyl groups forming a narrow rim. ${ }^{3}$ Hence, $\mathrm{CD}$ is very proficient in forming stable supramolecular host-guest inclusion complex with a variety of molecules for having a hollowcylindrical shaped cavity. ${ }^{4}$ Due to its special structure and prospective application in the discovery of molecular switches, molecular machines and supramolecular polymers, macrocyclic $\mathrm{CD}$ molecules are useful in chemistry. ${ }^{5}$ In some case, due to micro-encapsulation of guest by $\mathrm{CD}$, various changes in physical and chemical properties occur such as fixation of very volatile substances, masking of the colour, smell and taste of substances, etc. ${ }^{6}$ In case of drug delivery devices and nano-sensors, the molecular recognition of the host for

\footnotetext{
*For correspondence
}

the functioning is owing to the conjugation of $\mathrm{CD}$ with a variety of nanoparticles. ${ }^{7}$

Tetrabutylammonium iodide ( but $_{4} \mathrm{NI}$ ), a quaternary ammonium compound, is a water soluble strong electrolyte which exhibits an assortment of physical, chemical and biological properties. The ionic solid has applications in chemical reactions as surface-active agents (due to the hydrophobic butyl groups), solvents, intermediate emulsifying agents, phase transfer catalyst and for pigment dispersal. ${ }^{8,9}$ Since but $_{4} \mathrm{NI}$ has the tendency of locating at the interface of two phases (liquid-liquid or solid-liquid) for introducing the continuity between two different phases, it is positively a phase transfer catalyst. Due to low cost and low toxicity of but ${ }_{4} \mathrm{NI}$, in recent times it is a promising substitute as a catalyst for functionalization of $\mathrm{C}-\mathrm{H}$ bonds. ${ }^{10,11} \mathrm{In}$ industrial usage, but $_{4} \mathrm{NI}$ acts as active ingredient for conditioners, antistatic agents, detergent sanitizers, softener for textiles, paper products, etc.

In this article, we explored the creation of host-guest inclusion complexes (ICs) of the ionic solid with $\alpha$ and $\beta-C D$ particularly towards their formation, stabilization, carrying and controlled release by diverse methods such as ${ }^{1} \mathrm{H}$ NMR, FT-IR, surface tension, conductivity, density, viscosity and refractive index measurements (Scheme 1). The present study describes both qualitative and quantitative results regarding the formation of ICs of $\alpha$ and $\beta$-cyclodextrin with but ${ }_{4}$ NI. This work highlights the inclusion of ionic solid into the hydrophobic cavity of $\alpha$ and $\beta$-CD. 

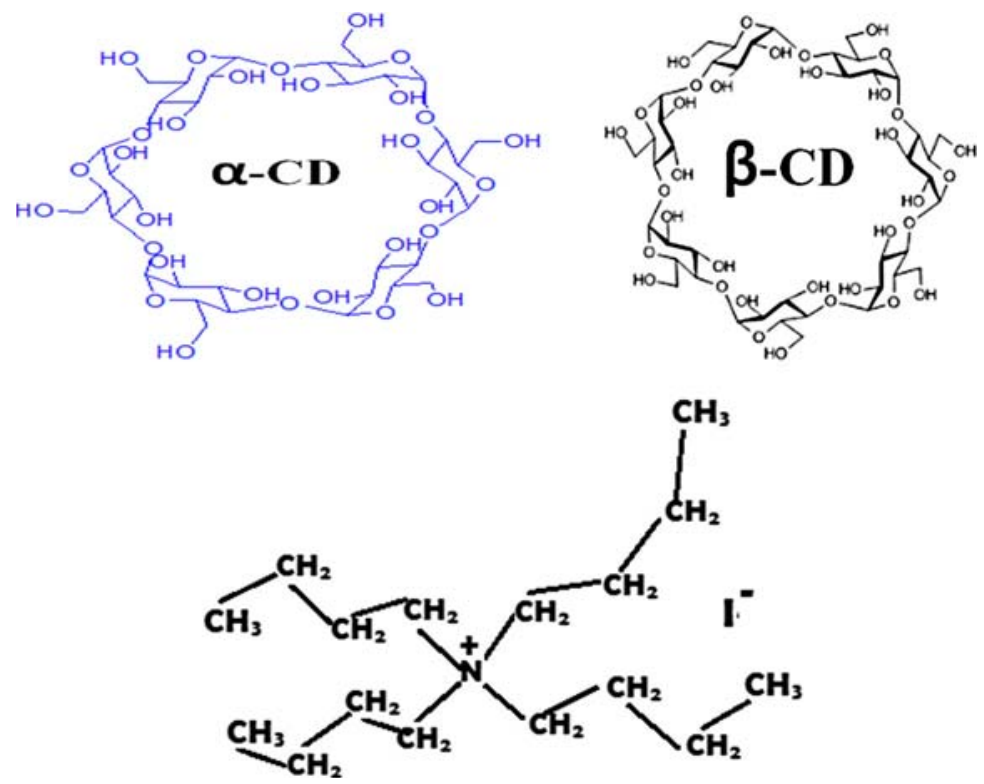

Scheme 1. Molecular structures of cyclodextrin molecules and tetrabutylammonium iodide.

\section{Experimental}

\subsection{Source and purity of samples}

Tetrabutylammonium Iodide but $_{4} \mathrm{NI}$ and cyclodextrins of 'puriss' grade were bought from Sigma-Aldrich, Germany and used as purchased. The mass fraction purities of but ${ }_{4} \mathrm{NI}$, $\alpha$ - and $\beta$-cyclodextrin were $\geq 0.99,0.98$ and 0.98 , respectively.

\subsection{Apparatus and procedures}

Stock solutions of $b_{4} t_{4} N I, \alpha-C D$ and $\beta-C D$ were prepared by mass (Mettler Toledo AG-285 with uncertainty $0.0001 \mathrm{~g}$ ) and by dilution at $298.15 \mathrm{~K}$ To change molarity of the solutions to molality, the density of the solutions was used. ${ }^{32}$

Using Bruker AVANCE $400 \mathrm{MHz}$ instrument at $298.15 \mathrm{~K}$. the NMR spectra were recorded in $\mathrm{D}_{2} \mathrm{O}$. Signals are cited as $\delta$ values in ppm using residual protonated solvent signals as internal standard $\left(\mathrm{D}_{2} \mathrm{O}: \delta 4.79 \mathrm{ppm}\right)$.

With the help of platinum ring detachment technique by a Tensiometer (K9, KRÜSS; Germany), surface tension (Accuracy $\pm 0.1 \mathrm{mN} \cdot \mathrm{m}^{-1}$ ) of the solution was measured at 298.15 $\mathrm{K}$. Temperature of the system was maintained by circulating thermostated water through a double-wall glass vessel holding the solution.

Conductivities of the solutions were studied by Mettler Toledo Seven Multi conductivity meter having uncertainty $1.0 \mu \mathrm{S} \mathrm{m}^{-1}$. The study was carried out in a thermostated water bath at $298.15 \mathrm{~K}$ with uncertainty $\pm 0.01 \mathrm{~K}$. HPLC grade water was used with specific conductance $6.0 \mu \mathrm{S} \mathrm{m}^{-1}$. The conductivity cell was calibrated using $0.01 \mathrm{M}$ aqueous $\mathrm{KCl}$ solution.

The densities $(\rho)$ of the solutions were measured by vibrating $U$-tube Anton Paar digital density meter (DMA 4500M) having precision of $\pm 0.00005 \mathrm{~g} \mathrm{~cm}^{-3}$ and uncertainty in tem- perature was $\pm 0.01 \mathrm{~K}$. The density meter was calibrated by standard method. ${ }^{30}$

Viscosities $(\eta)$ were determined by Brookfield DV-III Ultra Programmable Rheometer with spindle size 42 . The detail has already been presented in our earlier report. ${ }^{16}$ Refractive indexes of the solutions were measured with a Digital Refractometer from Mettler Toledo having uncertainty of \pm 0.0002 units.

To prepare both the solid inclusion complexes ([but $\left.{ }_{4} \mathrm{NI}\right]+$ $\alpha-\mathrm{CD}$ and $\left[\right.$ but $\left.\left._{4} \mathrm{NI}\right]+\beta-\mathrm{CD}\right), 1: 1$ molar ratio of the but ${ }_{4} \mathrm{NI}$ and cyclodextrin were taken. In both the cases, $1.0 \mathrm{mmol}$ cyclodextrin was dissolved in $20 \mathrm{~mL}$ water and $1.0 \mathrm{mmol}$ but $_{4} \mathrm{NI}$ was dissolved in $20 \mathrm{~mL}$ ethanol and stirred separately for $3 \mathrm{~h}$. Then, the ethanol solution of the ionic solid was added drop by drop to the aqueous $\mathrm{CD}$ solution. The mixture was then allowed to stir for $48 \mathrm{~h}$ at $50-55^{\circ} \mathrm{C}$. It was filtered, then cooled to $5^{\circ} \mathrm{C}$ and kept for $12 \mathrm{~h}$. The resulting suspension was filtered and the white polycrystalline powder was washed with ethanol and dried in air.

Fourier transform infrared (FT-IR) spectra were recorded on a Perkin Elmer FT-IR spectrometer using the $\mathrm{KBr}$ disk technique. Samples were prepared as $\mathrm{KBr}$ disks with $1 \mathrm{mg}$ of complex and $100 \mathrm{mg}$ of KBr. The FTIR measurements were performed in the scanning range of $4000-400 \mathrm{~cm}^{-1}$ at room temperature.

\section{Results and Discussion}

\section{1 ${ }^{1}$ H NMR study establishes inclusion}

The inclusion of the guest ionic solid inside the host CD molecule was ascertained by the most reliable NMR study. We have studied the interactions of but ${ }_{4} \mathrm{NI}$ with $\alpha$ - and $\beta$-CD. 1:1 molar ratio, by ${ }^{1} \mathrm{H}$ NMR at 298.15 K (Figure 1). Table S1 (in Supplementary Information) 
(a)

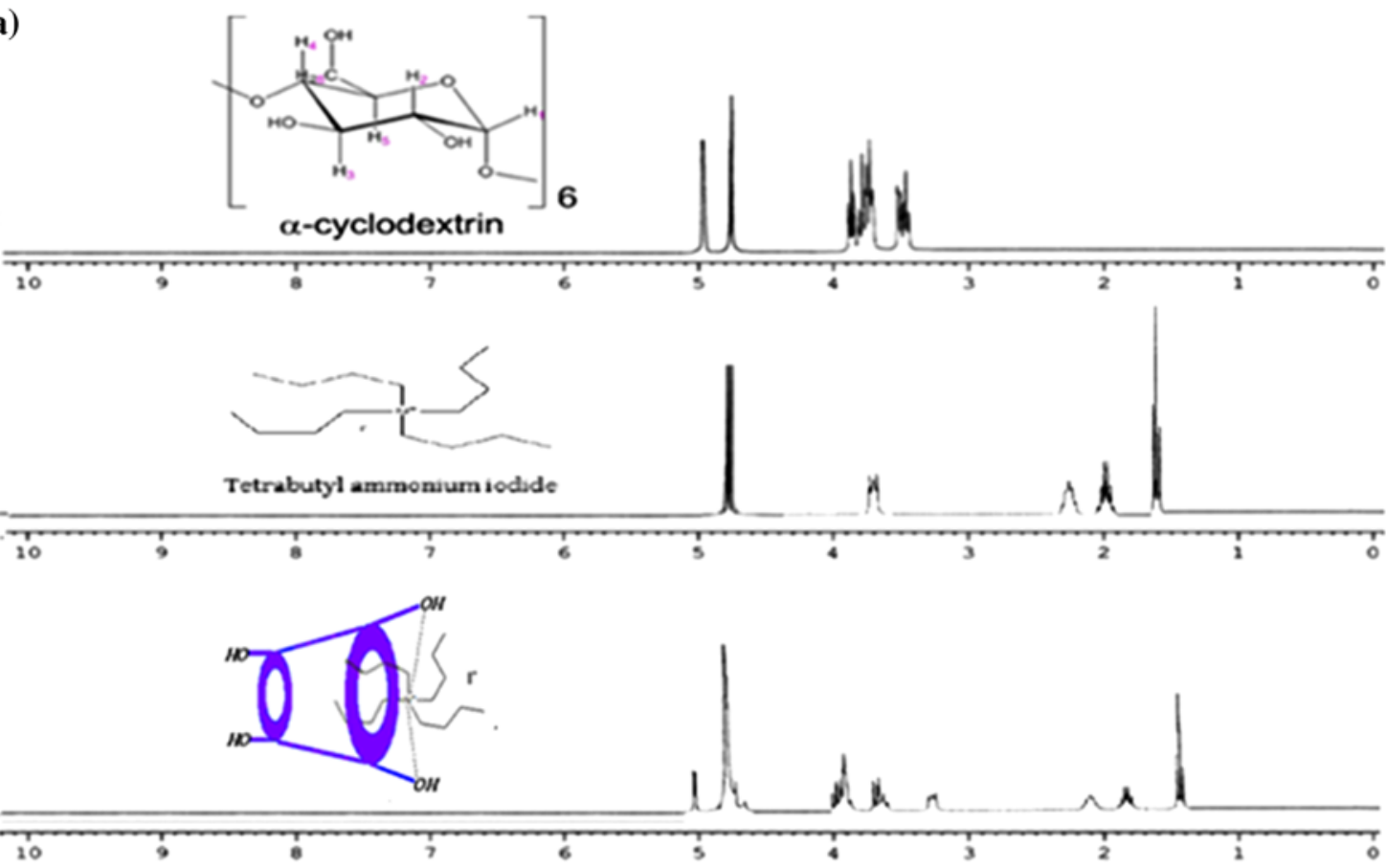

(b)
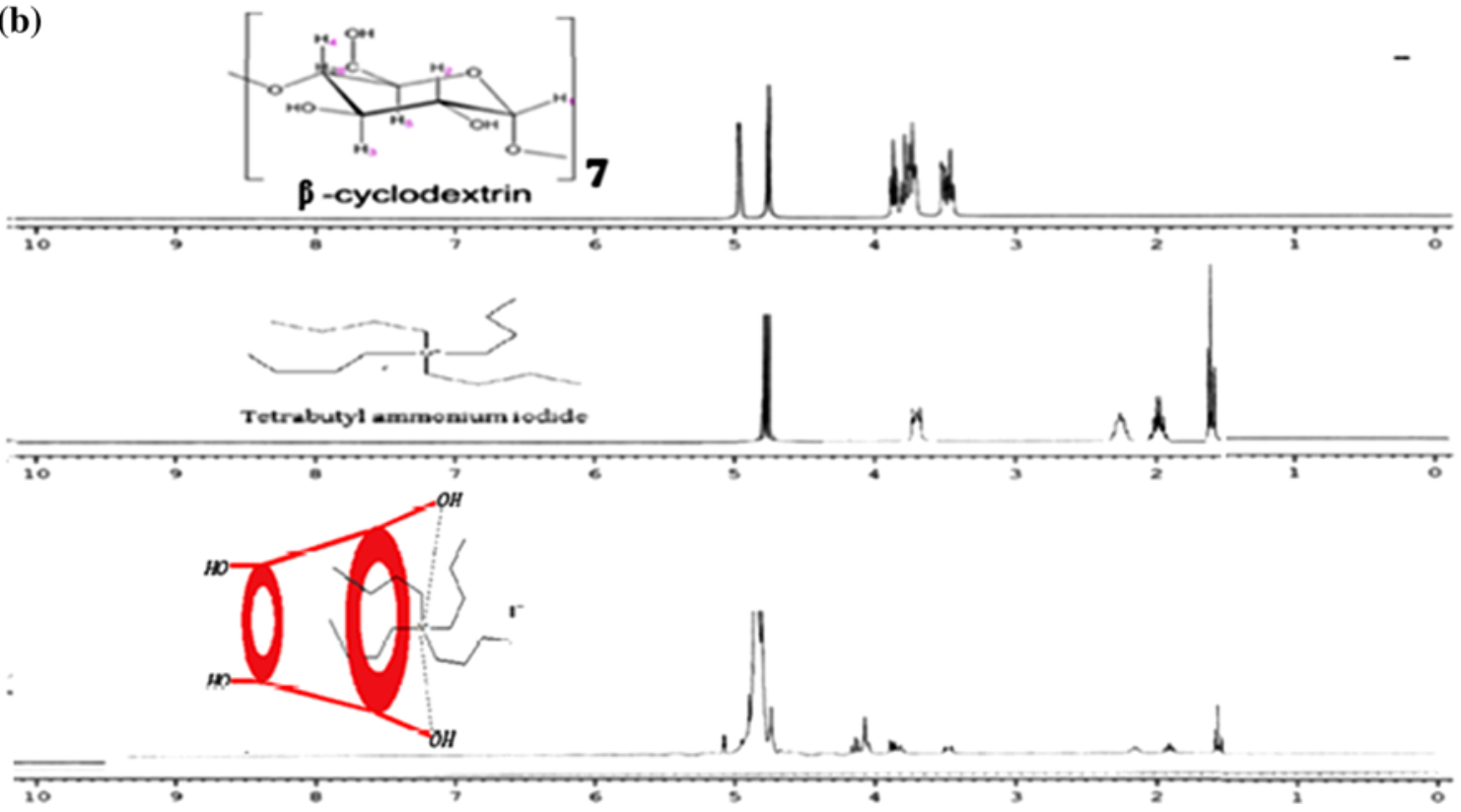

Figure 1. (a) ${ }^{1} \mathrm{H}$ NMR Spectra of $\alpha$-CD, Tetrabutyl ammonium iodide and 1:1 molar ratio of $\alpha$-CD+ Tetrabutyl ammonium iodide in $\mathrm{D}_{2} \mathrm{O}$ at $298.15 \mathrm{~K}$. (b) ${ }^{1} \mathrm{H}$ NMR Spectra of $\beta$-CD, Tetrabutyl ammonium iodide and 1:1 molar ratio of $\beta-\mathrm{CD}+$ Tetrabutyl ammonium iodide in $\mathrm{D}_{2} \mathrm{O}$ at $298.15 \mathrm{~K}$.

shows the ${ }^{1} \mathrm{H}$ NMR data of the but ${ }_{4} \mathrm{NI}$, two CDs and two ICs. Due to the incorporation of guest ionic solid into the hydrophobic cavity of $\mathrm{CD}$, the protons of the CD molecule show considerable chemical shift. ${ }^{12}$ In the structure of $\mathrm{CD}$, the $\mathrm{H} 1, \mathrm{H} 2$ and $\mathrm{H} 4$ (Figure 2) protons are at the periphery of $\mathrm{CD}$ molecule while the $\mathrm{H} 3$ and H5 are located within the cavity; more specifically, the location of $\mathrm{H} 3$ and $\mathrm{H} 5$ protons are near the wider rim and narrower rim, respectively. ${ }^{13,14}$ The $\mathrm{H} 3$ and $\mathrm{H} 5$ protons of CD show upfield chemical shift as a result of interaction with the guest in IC. It confirms the formation of host-guest inclusion complexes. The H3 proton located near the wider rim shows higher shift than the H5 proton which is present near the narrower rim at 


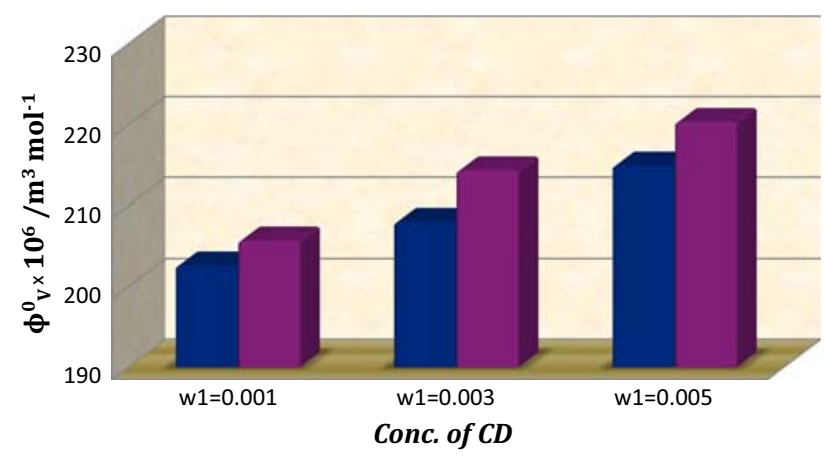

Figure 2. Plot of limiting molar volume $\left(\phi_{V}^{O}\right)$ against mass fraction $(w)$ of aqueous $\alpha-\mathrm{CD}$ (blue) and aqueous $\beta$-CD (purple) for but 4 NI at $298.15 \mathrm{~K}$.

the interior of $\mathrm{CD}$ due to insertion of guest ionic solid molecule inside the cavity of host CD through the wider rim (Scheme S1 in Supplementary Information). Due to the peripheral protons, upfield chemical shift is also observed but to a minor extent. The interacting protons of but ${ }_{4} \mathrm{NI}$ also show upfield chemical shift. The shifts of four protons present in each butyl group give four shifts which exemplifies the insertion mechanism. Moreover, the extent of shifts of butyl protons are more in $\beta$-CD compared to those in $\alpha-C D$, signifying that the binding affinity of the former is higher compared to the latter.

\subsection{Surface tension study supports inclusion}

Surface tension $(\gamma)$ is an important consideration which supports the inclusion complex formation of Tetrabutyl ammonium iodide with both $\alpha$ and $\beta$-CD. ${ }^{15}$ There is no considerable change to the surface tension of water when $\mathrm{CD}$ is added to pure water. This indicates that both $\alpha$ - and $\beta$-CD are almost surface inactive compounds. ${ }^{16}$ In our present work, the $\gamma$ values of aqueous ionic solid have been determined with addition of $\alpha$ - and $\beta$-CD at $298.15 \mathrm{~K}$ (Table S4-S5 in SI). With increasing concentration of CDs, the $\gamma$ values substantially increase for this ionic solid, but ${ }_{4} \mathrm{NI}$. This is due to the removal of surface active but ${ }_{4} \mathrm{NI}$ molecules from surface of the solution, i.e., $\alpha$ - and $\beta$-CD form the host-guest inclusion complexes after entry of the hydrophobic tail of but ${ }_{4} \mathrm{NI}$ into the hydrophobic cavity of $\alpha$ - and $\beta$-CD. ${ }^{17,18}$ Figure 3 and Table 1 show the formation of 1:1 inclusion complex of but ${ }_{4} \mathrm{NI}$ and CDs, both the curves show a single break point and after that point, the $\gamma$ value increases more slowly. Inclusion complex formation with stoichiometry such as $1: 2,2: 1,2: 2$, etc., occurs only if the surface tension curve shows more than one break point (Scheme S2 in SI). ${ }^{19,20}$ Table 1 shows the values of $\gamma$ and the corresponding concentration of CDs and but $_{4} \mathrm{NI}$ at the break point. The breaks have originated at a certain concentration of but ${ }_{4} \mathrm{NI}$ and $\mathrm{CD}$ where their concentration ratio in the solution is almost $1: 1$. Hence, this study proves the formation of 1:1 inclusion complex. In this case, the $\gamma$ value at the break point is higher for $\beta-C D$ than that of $\alpha-C D$ which suggests that the former is superior to encapsulate the guests than the afterward.

\subsection{Conductivity study notifies inclusion}

Conductivity $(\kappa)$ study validates the host-guest inclusion complex and also provides the stoichiometry of the complex. ${ }^{21,22}$ We have measured the conductivity of the aqueous solution of but ${ }_{4} \mathrm{NI}$ having $10 \mathrm{mM}$ concentration with successive addition of $\alpha$ - and $\beta-C D$ at $298.15 \mathrm{~K}$ (Table S4-S5 in SI). It was found that the conductivity of the ionic solid decreases on a usual basis with increasing concentration of CDs (Figure 4). Since the guest but ${ }_{4} \mathrm{NI}$ is inserted inside the cavity of the CD molecule, the number of free ions per unit volume reduces. Consequently, the conductivity of the solution decreases. Perusal of Figure 4 and Table 2 shows results analogous with suface tension study, each having a perceptible break point, signifying the formation of but $_{4}$ NI-CD inclusion complex having stoichiometry $1: 1$. Table 2 shows the values of $\kappa$ and corresponding concentration of but ${ }_{4} \mathrm{NI}$ and $\mathrm{CDs}$ at the break point.

\subsection{Density study: interaction between host and guest}

In this study, important information about the inclusion phenomenon between the ionic solid and CD molecules have been obtained from density measurements. Apparent molar volume $\left(\phi_{\mathrm{v}}\right)$ and limiting apparent molar volume $\left(\phi_{\mathrm{v}}^{\mathrm{o}}\right)$ are the two major parameters used for this study. Apparent molar volume $\left(\phi_{\mathrm{v}}\right)$ mainly describes the summation of the geometric volume of the central solute molecule and changes in the solvent volume as a result of interface with the solute around the co-sphere (here, solute $=$ but $_{4} \mathrm{NI}$ and co-solvent $\left.=\mathrm{CD}\right) .{ }^{23}$ For this system (ternary phase of but ${ }_{4} \mathrm{NI}+$ aqueous CD system), solute-solvent interaction is conveyed by limiting apparent molar volume. For this study, $\phi_{\mathrm{v}}$ have been calculated from the density of solutions at $298.15 \mathrm{~K}$ by means of eq. (5) as described in Supplementary Information (Table S6). Least squares method was employed to the plots of $\phi_{\mathrm{v}}$ versus $\sqrt{ } m$ using the Masson equation (eq. 6, Table S7 in SI) for obtaining $\phi_{\mathrm{v}}^{\mathrm{o}}$ value. ${ }^{24} \mathrm{It}$ was found that $\phi_{\mathrm{v}}$ values are reduced and $\phi_{\mathrm{v}}^{\mathrm{o}}$ values are continually enhanced for but ${ }_{4} \mathrm{NI}$ with increasing concentration of both the CDs. It is manifest from this fact 

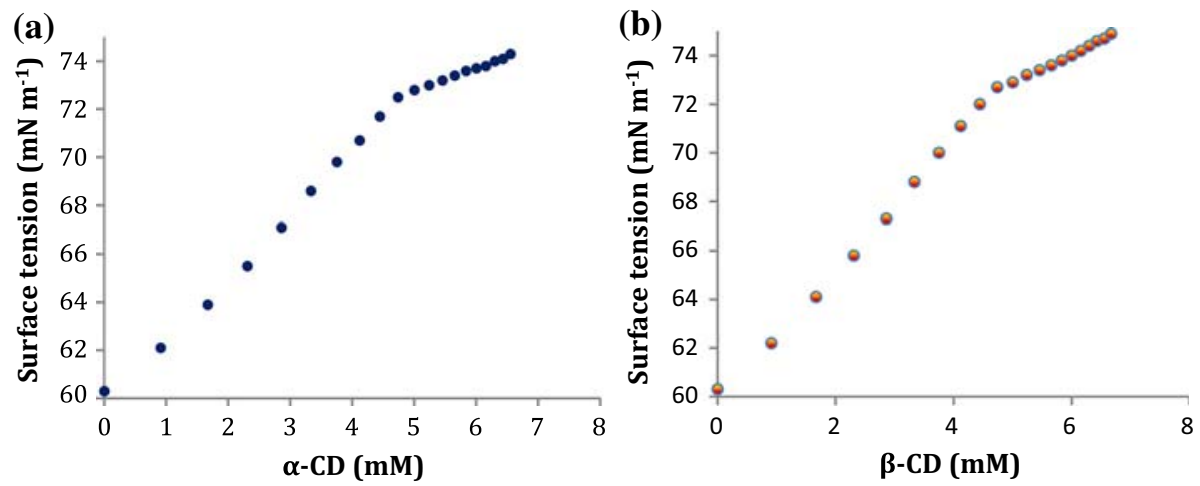

Figure 3. Variation of surface tension of aqueous solutions at 298.15 K. (a) but ${ }_{4} \mathrm{NI}-\alpha-\mathrm{CD}$ and (b) but $\mathrm{t}_{4} \mathrm{NI}-\beta-\mathrm{CD}$.

Table 1. Values of surface tension $(\gamma)$ at the break point with corresponding concentrations of cyclodextrins and but 4 NI at $298.15 \mathrm{~K}^{\mathrm{a}}$.

\begin{tabular}{llll} 
but $_{4} \mathrm{NI}$ & & & \\
\hline Name of the host & Conc. of host $/ \mathrm{mM}$ & Conc. of but $4 \mathrm{~N} / \mathrm{mM}$ & $\gamma^{\mathrm{a}} / \mathrm{mN} \cdot \mathrm{m}^{-1}$ \\
\hline$\alpha-\mathrm{CD}$ & 4.89 & 5.10 & 72.67 \\
$\beta-\mathrm{CD}$ & 4.77 & 5.23 & 73.52 \\
\hline
\end{tabular}

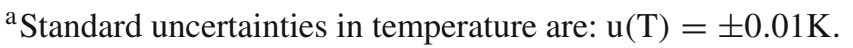
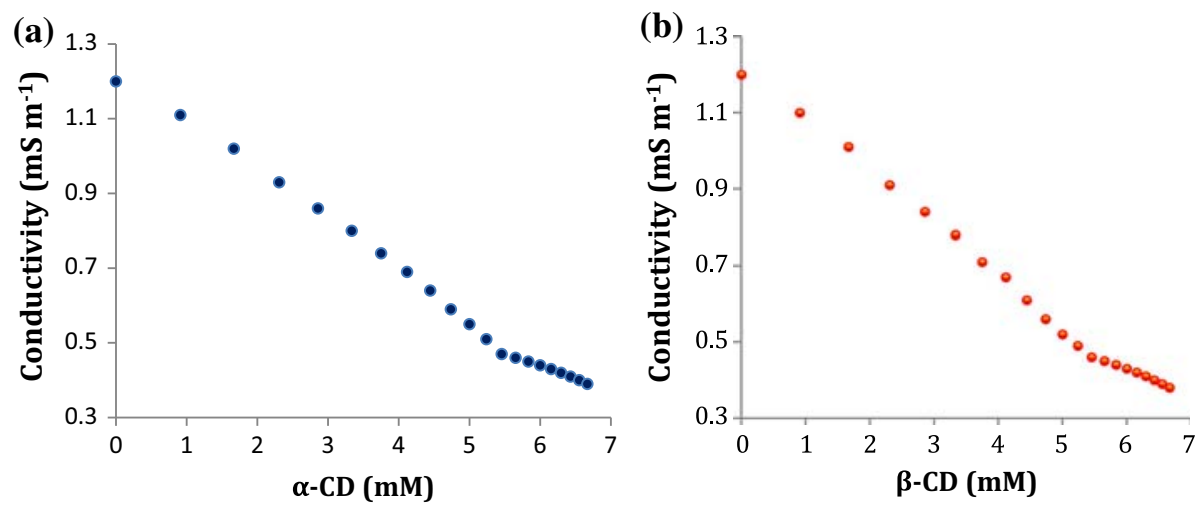

Figure 4. Variation of conductivity of aqueous systems at $298.15 \mathrm{~K}$. (a) but ${ }_{4} \mathrm{NI}-\alpha-\mathrm{CD}$ and (b) but ${ }_{4} \mathrm{NI}-\beta-\mathrm{CD}$.

Table 2. Values of conductivity $(\kappa)$ at the break point with corresponding concentrations of cyclodextrins and but 4 NI at $298.15 \mathrm{~K}^{\mathrm{a}}$.

\begin{tabular}{llll}
\hline but ${ }_{4} \mathrm{NI}$ & & & \\
\hline Name of the host & Conc. of host $/ \mathrm{mM}$ & Conc of but ${ }_{4} \mathrm{NI} / \mathrm{mM}$ & $\mathrm{\kappa}^{\mathrm{a}} / \mathrm{mS} \cdot \mathrm{m}^{-1}$ \\
\hline$\alpha-\mathrm{CD}$ & 5.91 & 4.09 & 0.40 \\
$\beta$-CD & 5.44 & 4.56 & 0.47 \\
\hline
\end{tabular}

${ }^{a}$ Standard uncertainties in temperature are: $\mathrm{u}(\mathrm{T})= \pm 0.01 \mathrm{~K}$. 


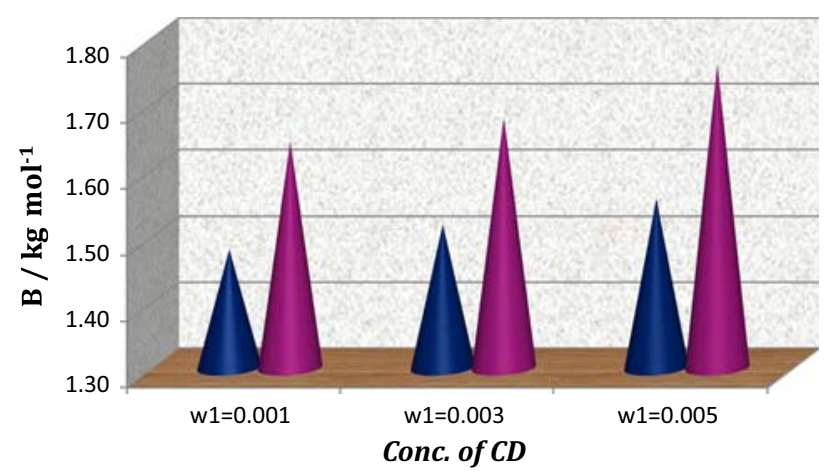

Figure 5. Plot of viscosity $B$-coefficient against mass fraction $(w)$ of aqueous $\alpha-\mathrm{CD}$ (blue) and aqueous $\beta$-CD (purple) for but 4 NI at $298.15 \mathrm{~K}$.

that for but $_{4} \mathrm{NI}$, in both the cases of $\alpha$ - and $\beta-\mathrm{CD}$, the ion-hydrophilic group interactions are more efficient than ion-hydrophobic group interactions. The inspection of Figure 2 shows that the value of $\phi_{\mathrm{v}}^{\circ}$ increases with increasing mass fractions of both $\mathrm{CDs}$, and greater for $\beta-C D$ than $\alpha-C D$, signifying that the former interacts more with but ${ }_{4} \mathrm{NI}$ than the latter. This may be explained as, in the case of but ${ }_{4} \mathrm{NI}$, two hydrophobic butyl groups can be encapsulated in the cavity of CD and the single positively charged $\mathrm{N}$ atom shows higher ion-hydrophilic interaction with the $-\mathrm{OH}$ groups of $\mathrm{CD}$. The larger diameter of $\beta$-CD helps in making a more compact inclusion complex with but ${ }_{4} \mathrm{NI}$ than $\alpha-\mathrm{CD}$ with a relatively smaller cavity size showing less hydrophobic interactions with but $_{4} \mathrm{NI}$.

\subsection{Viscosity study: order of interactions}

Viscosity study is also fruitful for the interpretation of interaction between ionic solid and CDs. ${ }^{25}$ In the present ternary system $\left(\right.$ but $_{4} \mathrm{NI}+$ aqueous $\mathrm{CD}$ ), (Table $\mathrm{S} 3$ in SI), the viscosity of the solutions show an increasing trend with increasing concentration of but ${ }_{4}$ NI. The size and shape of the solute molecule recommend the solute-solvent interaction (here, solute $=$ but $_{4} \mathrm{NI}$ and co-solvent $=\mathrm{CD}$ ) which is designated as viscosity $B$-coefficients (Table S7 in SI). ${ }^{26}$ All the viscosity $B$ coefficient values were found to be positive and depicted in Figure 5. Perhaps due to higher solvation and also greater but ${ }_{4}$ NI-CD interaction, the viscosity $B$ values increase with increasing concentration of CDs. ${ }^{17}$ Since the viscosity $B$ values is again larger for $\beta-C D$ than for $\alpha-C D$, it suggests that inclusion complex is more constructive in the case of former than the latter. The structural features of but ${ }_{4} \mathrm{NI}$ and CDs for which these trends of interactions have relative consequences in viscosity study are analogous to the density study.

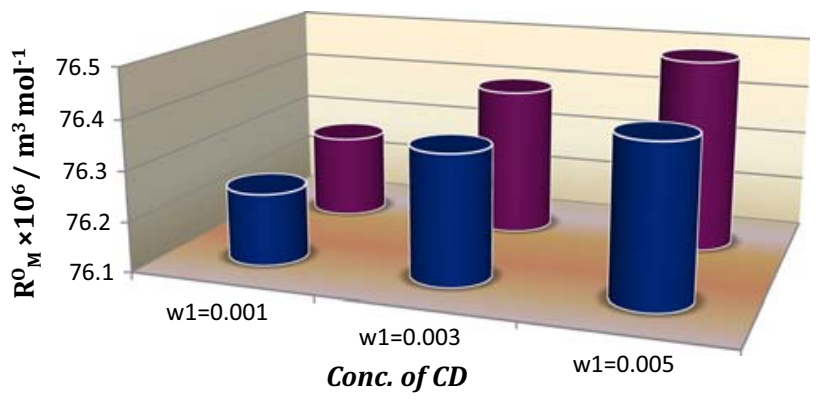

Figure 6. Plot of limiting molar refraction $\left(R_{M}^{0}\right)$ for but ${ }_{4} \mathrm{NI}$ in different mass fractions $(w)$ in aqueous solutions of $\alpha$-CD (blue) and aqueous $\beta$-CD (purple), respectively, at $298.15 \mathrm{~K}$.

\subsection{Refractive index shows the compactness of the inclusion complexes}

To establish the molecular interaction in the above mentioned ternary solutions, refractive index is one more important parameter to ascertain the molecular interaction. ${ }^{15}$ Using the suitable equation (Tables S3 and S6 in SI), refractive index $\left(n_{\mathrm{D}}\right)$ and molar refraction $\left(R_{\mathrm{M}}\right)$ values of the solutions have been estimated. The compactness and density of the medium were determined by the greater values of $R_{\mathrm{M}}$ and the limiting molar refraction $\left(R_{\mathrm{M}}^{\mathrm{O}}\right)$ (Table S7). ${ }^{16,17}$ In the case of but ${ }_{4} \mathrm{NI}$ in both $\alpha$ - and $\beta-\mathrm{CD}$, the $R_{M}^{O}$ values show an increasing trend with increasing concentration of both CDs, which suggest that the IC of but ${ }_{4} \mathrm{NI}$ with both the CDs are more closely packed, perhaps due to greater hydrophobic as well as ion-hydrophilic interactions between the guest and host as described earlier. The $R_{\mathrm{M}}^{\mathrm{O}}$ values designate that $\beta$-CD is more favourable than $\alpha-C D$ for formation of the ICs (Figure 6). The density and viscosity studies (Sects. 3.4 and 3.5) are in concurrence with the observations obtained from refractive index data.

\subsection{FT-IR spectra of solid inclusion complexes}

The inclusion phenomena are nicely proved by FT-IR spectrum. ${ }^{27-29}$ Table S8 (in SI) refers to the characteristic IR frequencies of $\alpha-C D, \beta-C D$, but ${ }_{4} \mathrm{NI}$ and solid ICs. Characteristic broad peaks of $-\mathrm{OH}$ at about $3412.10 \pm$ $0.01 \mathrm{~cm}^{-1}$ and $3349.84 \pm 0.01 \mathrm{~cm}^{-1}$ are here in the spectrum for and $\beta-C D$, respectively. The FT-IR Spectrum of but ${ }_{4} \mathrm{NI}$ shows the presence of peaks for $-\mathrm{N}-\mathrm{C}-\mathrm{H}-,-\mathrm{C}-$ $\mathrm{H}$ (stretching), - $\mathrm{C}-\mathrm{H}$ (bending for $-\mathrm{CH}_{3}$ group), $-\mathrm{C}-\mathrm{H}$ (bending for $-\mathrm{CH}_{2}$ group), etc. (Figures $7(\mathrm{a}),(\mathrm{b})$ and Table S8). Yet, there are several either absent or shifted peaks of the but ${ }_{4} \mathrm{NI}$ due to the change in atmosphere of the guest after inclusion in the $\mathrm{CD}$ cavity. The $-\mathrm{C}-\mathrm{H}$ bending bands for $-\mathrm{CH}_{3}$ and $-\mathrm{CH}_{2}$ of both the but ${ }_{4} \mathrm{NI}$ are shifted in the spectrum of the inclusion complex. The - 
(a)

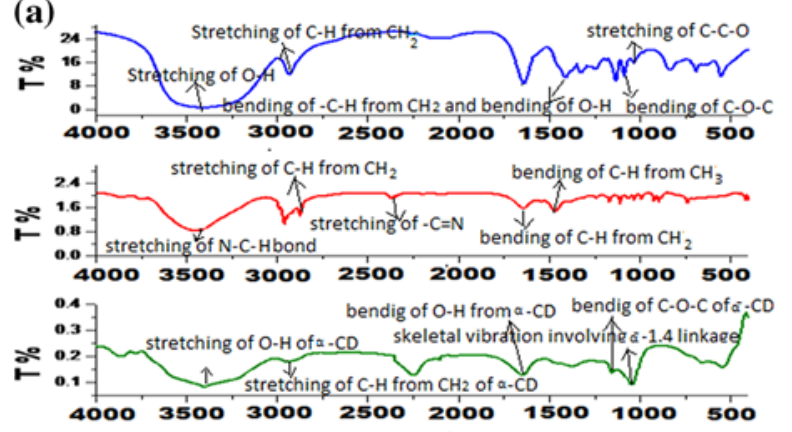

(b)

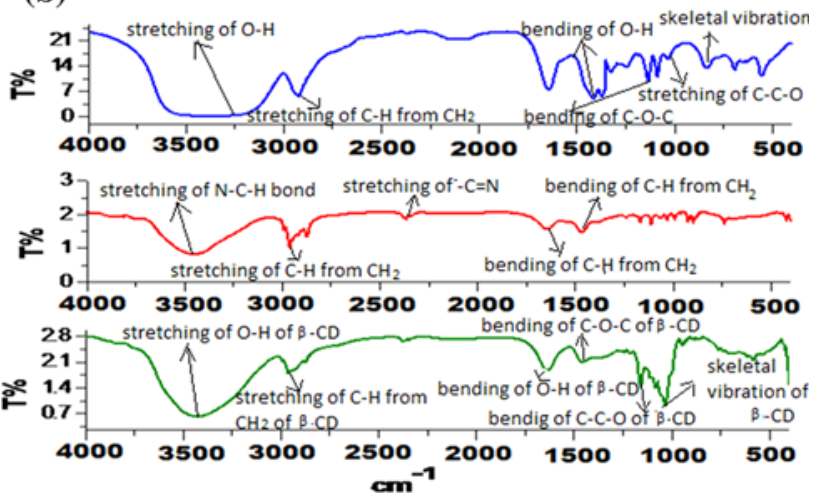

Figure 7. (a) FTIR spectra of $\alpha-\mathrm{CD}$ (top), but ${ }_{4} \mathrm{NI}$ (middle) and but ${ }_{4} \mathrm{NI}-\alpha-\mathrm{CD}$ inclusion complex (bottom). (b) FTIR spectra of $\beta-\mathrm{CD}\left(\right.$ top), but $_{4} \mathrm{NI}$ (middle) and but 4 NI- $\beta$-CD inclusion complex (bottom).

$\mathrm{O}-\mathrm{H}$ stretching of $\alpha-\mathrm{CD}$ is shifted to lower frequency in the spectrum of the IC, probably due to involvement of the -O-H groups of the host molecules in hydrogen bonding with the guest molecule. On the other hand the $-\mathrm{O}-\mathrm{H}$ stretching of $\beta-\mathrm{CD}$ is shifted to higher frequency in the IC, probably due to involvement of the $-\mathrm{O}-\mathrm{H}$ groups of the host molecules in hydrogen bonding with the guest molecule. In the spectrum of the ICs, the peak for the $\mathrm{C}-\mathrm{N}$ group of the guest molecule is present. It is an indication that the hydrophobic side chains present on one side of the polar $\mathrm{N}$ atom of the guest molecules are encapsulated in the hydrophobic cavity of both the CDs.

\subsection{Binding constants: non-linear isotherms determined by conductivity method}

1:1 host-guest inclusion complex formation of ionic solid (IS), but ${ }_{4} \mathrm{NI}$ with $\alpha$ - and $\beta$-CD can be represented by this equilibrium:

$$
I S+C D \stackrel{K_{f}}{\longleftrightarrow} I C
$$

The corresponding equilibrium constant, $K_{f}$ is given by,

$$
K_{f}=\frac{[I C]}{[I S][C D]} \times \frac{f(I C)}{f(I S) f(C D)}
$$

Table 3. Formation constants of but NII $^{-}$ cyclodextrin inclusion complexes.

\begin{tabular}{llll}
\hline Cyclodextrin & \multicolumn{3}{l}{$\log \mathrm{K}_{f}^{\mathrm{b}}\left(\mathrm{M}^{-1}\right)$} \\
\cline { 2 - 4 } & $298.15 \mathrm{~K}^{\mathrm{a}}$ & $303.15 \mathrm{~K}^{\mathrm{a}}$ & $308.15 \mathrm{~K}^{\mathrm{a}}$ \\
\hline$\alpha-\mathrm{CD}$ & 3.12 & 2.95 & 2.78 \\
$\beta-\mathrm{CD}$ & 3.38 & 3.15 & 2.99 \\
\hline
\end{tabular}

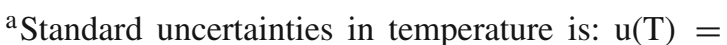
$\pm 0.01 \mathrm{~K}$. ${ }^{\mathrm{b}}$ Mean error in $\mathrm{K}_{\mathrm{b}}= \pm 0.01 \times 10^{-3} \mathrm{M}^{-1}$.

where $[I C],[I S],[C D]$ and $f$ represent the equilibrium molar concentrations of the inclusion complex, Ionic solid, CDs and the activity coefficients of the species, respectively. Using the dilute solution system, the activity coefficient of uncharged macrocycle, $f(C)$, can be reasonably assumed as unity. The use of Debye-Hückel limiting law, ${ }^{30}$ we conclude that $f(I S) \sim f(C D)$, so the activity coefficients in Eq. (2) are cancelled. The complex formation constant in terms of the molar conductance, $\Lambda$, can be expressed as, ${ }^{31}$

$$
\begin{gathered}
K_{f}=\frac{[I C]}{[I S][C D]}=\frac{\left(\Lambda_{I S}-\Lambda_{o b s}\right)}{\left(\Lambda_{o b s}-\Lambda_{I C}\right)[C D]} \\
\text { where }[C D]=C D_{a d}-\frac{I S_{a d}\left(\Lambda_{I S}-\Lambda_{o b s}\right)}{\left(\Lambda_{I S}-\Lambda_{I C}\right)}
\end{gathered}
$$

Here, $\Lambda_{I S}$ represents molar conductance of the ionic solid before the addition of $\mathrm{CD}, \Lambda_{I C}$ the molar conductance of the inclusion complex, $\Lambda_{o b s}$ the molar conductance of the solution during titration, $C D_{a d}$ the concentration of added cyclodextrin and $[I S]$ concentration of the ionic solid. The complex formation constant, $K_{f}$ and the molar conductance of the complex, $\Lambda_{I C}$ were evaluated by using Eqs. (3) and (4). Through the application of a non-linear programme, the $K_{f}$ values (Table 3 ) for the ICs were assessed from the binding isotherm.

$K_{f}$ values indicate that the but $_{4} \mathrm{NI}$ has higher binding constant in $\beta$-CD than in $\alpha-C D$. This fact may be due to the larger cavity dimension of $\beta-C D$ than that of $\alpha-C D$. So, inclusion complex formation is highly feasible in $\beta$-CD than in $\alpha$-CD.

\subsection{Structural influence of cyclodextrin in inclusion complex formation}

The formation of host-guest ICs between the Ionic solid and CDs is dependent on the size of the guest molecule and also on the cavity diameter of the host. Between the two CDs, $\beta$-CD has the higher cavity diameter (6.0-6.5 $\AA$ ) than that of $\alpha-C D(4.7-5.3 \AA)$. In view of the com- 
patible size of the but ${ }_{4} \mathrm{NI}$ with $\beta-\mathrm{CD}$, it is found that $\beta$-CD is more apt to form IC than $\alpha$-CD with but ${ }_{4} \mathrm{NI}$, possibly due to higher surface interaction, escalating the hydrophobic attractions, which is in concurrence with spectroscopic and physicochemical data. ${ }^{1}$ In the case of ICs, no covalent bonds are formed or broken, only the hydrophobic alkyl chains of but ${ }_{4} \mathrm{NI}$ are encapsulated in the hydrophobic cavity of CD molecules. This is a very important factor for IC formation that the hydrophobic cavity of CD is engaged by polar water molecule, but it is unfavourable, so the water molecules are effortlessly replaced by more hydrophobic alkyl tails of but ${ }_{4}$ NI. Furthermore, due to the release of the trapped water molecules in the bulk of the solution, entropy of the solution is enhanced and the IC formation becomes spontaneous. Due to the spontaneity, the system becomes energetically very low and stable. So, the ring strain of CD molecule becomes very low. Due to the difficulty of the trapping of another but ${ }_{4} \mathrm{NI}$ by CD molecule, 1:1 host-guest inclusion complex formation occurs. The stability of the IC can be ascribed to structural features such that the $\mathrm{N}$ atom present in but $_{4} \mathrm{NI}$ form $\mathrm{H}$-bonds with the $-\mathrm{OH}$ groups present at the rim of CD.

\section{Conclusions}

The above described physicochemical studies help us to conclude that the ionic solid, tetrabutyl ammonium iodide forms host-guest inclusion complexes with $\alpha$ and $\beta$-CD in solution and in solid state. With the help of ${ }^{1} \mathrm{H}$ NMR study, it is substantiated that inclusion occurs in the apolar cavity of both CD molecules, even as surface tension and conductivity data suggested 1:1 stoichiometry. Density, viscometric and refractometric measurements were also in excellent concord with this, and furthermore, suggested interactions between the ionic solid and CD. The solid state ICs were characterised by FT-IR. In this study, the inclusion phenomenon of ionic solid originated more favourably in case of $\beta-\mathrm{CD}$ than in $\alpha-\mathrm{CD}$. The binding constants, evaluated using a non-linear programme by the conductivity method, also support the trend in IC formation.

\section{Supplementary information (SI)}

All the data of physicochemical data (e.g., surface tension, conductivity, density, viscosity and refractive index) as well as spectroscopic data (e.g., NMR and IR spectra), are given in Supplementary Information. Theories and equations for all the studied physicochemical properties are also given in Supplementary Information. Supplementary Information (SI) for this article (Theory, Tables S1-S8 and Schemes S1-S2) is available at www.ias.ac.in/chemsci.

\section{Acknowledgements}

The authors are immensely grateful to SAP, Department of Chemistry, NBU under University Grants Commission (UGC), New Delhi. M. N. R. is obliged to University Grants Commission, New Delhi, Government of India for the award of one time grant under Basic Scientific Research for his dynamic service in the sophisticated research work.

\section{References}

1. Szejtli J 1998 Introduction and General Overview of Cyclodextrin Chemistry Chem. Rev. 981743

2. Connors K A 1997 The Stability of Cyclodextrin Complexes in Solution Chem. Rev. 971325

3. Pinho E, Grootveld M, Soarse G and Henriques M 2014 Cyclodextrins as Encapsulation Agents for Plant Bioactive Compounds Carbohydr. Polym. 101121

4. Wei B 2015 Corrigendum to " $\beta$-Cyclodextrin associated polymeric systems: Rheology, flow behavior in porous media and enhanced heavy oil recovery performance Carbohydr. Polym. 134398

5. Yu, G, Hua B and Han C 2014 Proton Transfer in Host-Guest Complexation between a Difunctional Pillar[5] arene and Alkyldiamines Org. Lett. 162486

6. Li H, Chen D, Sun Y, Zheng, Y B, Tan L, Weiss P S and Yang Y 2013 Cyclodextrin-Modified Gold Nanospheres. Host-Guest Interactions at Work to Control Colloidal Properties J. Am. Chem. Soc. 1351570

7. Welton T 1999 Room-Temperature Ionic Liquids. Solvents for Synthesis and Catalysis Chem. Rev. 992071

8. Winter B, Weber R, Schmidt P M and Hertel I V 2004 Photoemission from Aqueous Alkali-Metal-Iodide Salt Solutions Using EUV Synchrotron Radiation J. Phys. Chem. B 10814558

9. Bergersen H, Marinho R R T, Pokapanich W, Lindblad A, Björneholm O, Sæthre L J and Öhrwall J G 2007 The Surface Behavior of Hydrated Guanidinium and Ammonium Ions: A Comparative Study by Photoelectron Spectroscopy and Molecular Dynamics Phys.: Condens. Matter 19326101

10. Li X, Xu X and Zhou C 2012 Visible-light induced oxidant-free oxidative cross-coupling for constructing allylic sulfones from olefins and sulfinic acids Chem. Commun. 4812240

11. Liu Z J, Zhang J, Chen S L, Shi E, Xu Y and Wan X B 2012 Cross coupling of acyl and aminyl radicals: Direct synthesis of amides catalyzed by $\mathrm{Bu}_{4} \mathrm{NI}$ with TBHP as an oxidant Angew. Chem. Int. Ed. 513231

12. Uyanik M, Okamoto F, Yasui T and Ishihara K 2010 Quaternary ammonium (hypo)iodite catalysis for enantioselective oxidative cycloetherification Science $\mathbf{3 2 8}$ 1376

13. Sindelar V, Cejas M A, Raymo F M, Chen W, Parker S E and Kaifer A E 2005 Supramolecular assembly of 2,7-dimethyldiazapyrenium and cucurbit[8]uril: A new 
fluorescent host for detection of catechol and dopamine Chem. Eur. J. 117054

14. Wang T, Wang M D, Ding C and Fu J 2014 Monobenzimidazole functionalized $\beta$-coumaric acid Chem. Commun. 5012469

15. Roy M N, Ekka D, Saha S and Roy M C 2014 Hostguest inclusion complexes of $\alpha$-amino acids $R S C A d v .4$ 42383

16. Roy M N, Roy A and Saha S 2016 Probing inclusion complexes of cyclodextrins with amino acids by physicochemical approach Carbohydr. Polym. 151 458

17. Saha S, Ray T, Basak S and Roy M N 2016 surface tension and conductivity studies to determine the inclusion mechanism: thermodynamics of host-guest inclusion complexes of natural amino acids in aqueous cyclodextrins New J. Chem. 40651

18. Gao Y A, Li Z H, Du J M, Hou W G, Shen D, Zheng L Q and Zhang G Y 2005 Preparation and characterization of inclusion complexes of $\beta$-cyclodextrin with ionic liquid Chem. Eur. J. 115875

19. Piñeiro Á, Banquy X, Pérez-Casas S, Tovar E, García A, Villa A, Amigo A, Mark A E and Costas M 2007 On the Characterization of Host-Guest Complexes: Surface Tension Calorimetry and Molecular Dynamics of Cyclodextrins with a Non-Ionic Surfactant J. Phys. Chem. B 1114383

20. Gao Y, Zhao X, Dong B, Zheng L, Li N and Zhang S 2006 Inclusion complexes of $\beta$-cyclodextrin with ionic liquid surfactants J. Phys. Chem. B 1108576

21. Roy M N, Saha S, Barman S and Ekka D 2016 Hostguest inclusion complexes of RNA nucleosides inside aqueous cyclodextrins explored by physicochemical and spectroscopic methods $R S C A d v .68881$
22. Apelblat A, Manzurola E and Orekhova Z 2007 Electrical Conductance Studies in Aqueous Solutions with Glutamic Ions J. Solut. Chem. 36891

23. Ekka D and Roy M N 2014 RSC Adv. 419831

24. Masson D O 1929 Solute Molecular Volumes in Relation to The Solvation and Ionization Phil. Mag. 8218

25. Roy A, Saha S and Roy M N 2016 Study to explore host-guest inclusion complexes of cyclodextrins with biologically active molecules in aqueous environment Fluid Phase Equilib. 425252

26. Jones G and Dole D 1929 The viscosity of aqueous solutions of strong electrolytes with special reference to barium chloride J. Am. Chem. Soc. 512950

27. Negi J S and Singh S 2013 Spectroscopic investigation on the inclusion complex formation between amisulpride and $\gamma$-cyclodextrin Carbohydr. Polym. 921835

28. Zhang W, Gong X, Cai Y, Zhang C, Yu X, Fan J and Diao G 2013 Investigation of water-soluble inclusion complex of hypericin with $\beta$-cyclodextrin polymer Carbohydr. Polym. 95366

29. Milovanovic S, Markovic D, Aksentijevic K, Stojanovic D B, Ivanovic J and Zizovic I 2016 Application of cellulose acetate for controlled release of thymol Carbohydr. Polym. 147344

30. Shamsipur M and Khayatian G 2001 Conductance Study of the Thermodynamics of $\mathrm{Tl}+$ ion Complexes with Different 18-Membered Crown Ethers in Binary Dimethyl formamide-Acetonitrile Mixtures J. Inclusion Phenom. 39109

31. Barman S and Roy M N 2016 Hollow circular compound-based inclusion complexes of an ionic liquid RSC Adv. 676381

32. Shoemaker D P and Garland C W 1967 In Experiments in Physical Chemistry (New York: McGraw-Hill) p.131 